ORNL/TM-2016/340

CRADA/NFE-15-05476

\title{
Additive Manufacturing of Near-net Shaped Permanent Magnets
}

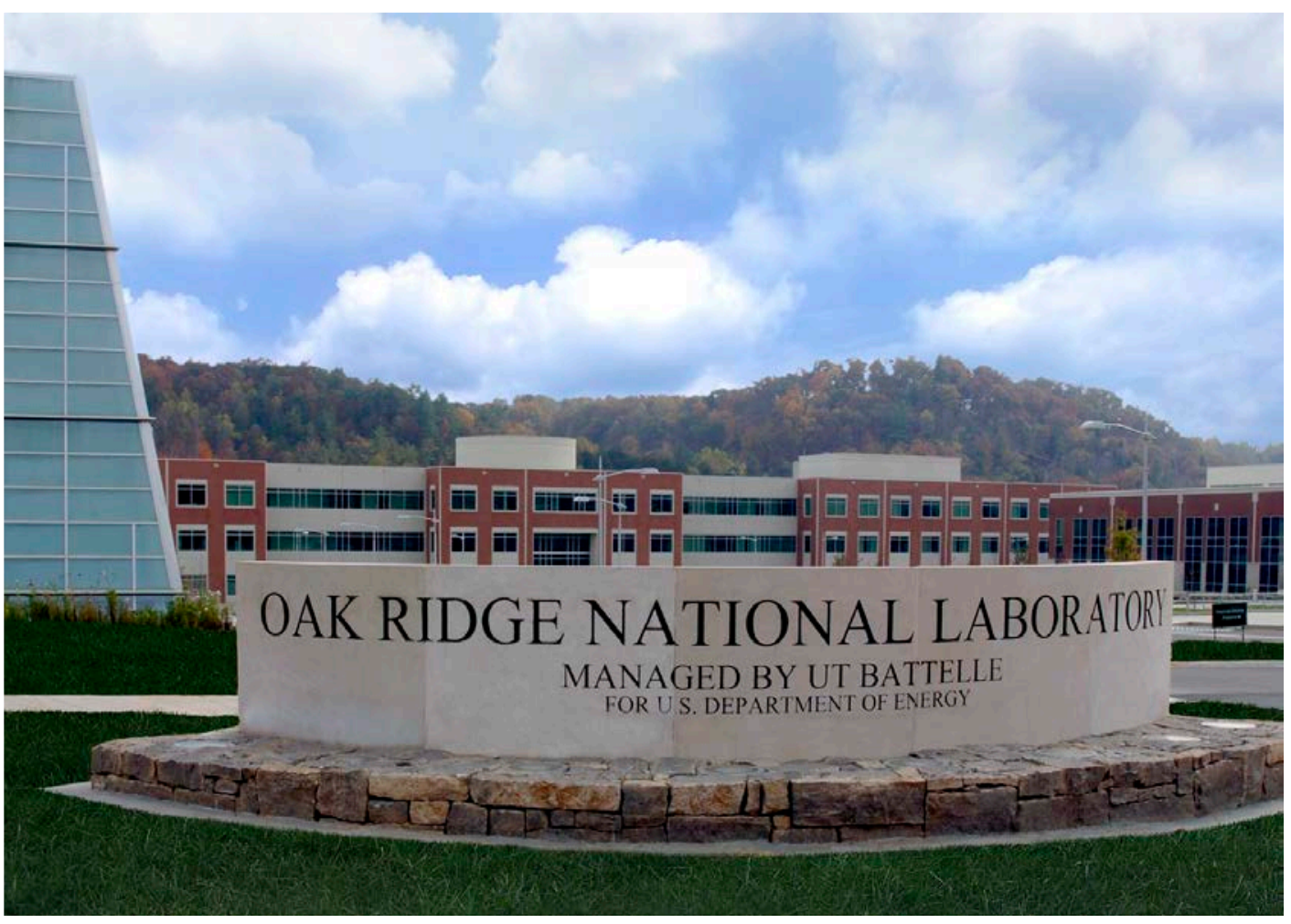

M. Parans Paranthaman

$07 / 26 / 2016$

CRADA FINAL REPORT NFE-15-05476

Approved for Public Release. Distribution is Unlimited. 


\section{DOCUMENT AVAILABILITY}

Reports produced after January 1, 1996, are generally available free via US Department of Energy (DOE) SciTech Connect.

Website http://www.osti.gov/scitech/

Reports produced before January 1, 1996, may be purchased by members of the public from the following source:

National Technical Information Service

5285 Port Royal Road

Springfield, VA 22161

Telephone 703-605-6000 (1-800-553-6847)

TDD 703-487-4639

Fax 703-605-6900

E-mail info@ntis.gov

Website http://www.ntis.gov/help/ordermethods.aspx

Reports are available to DOE employees, DOE contractors, Energy Technology Data Exchange representatives, and International Nuclear Information System representatives from the following source:

Office of Scientific and Technical Information

PO Box 62

Oak Ridge, TN 37831

Telephone 865-576-8401

Fax 865-576-5728

E-mail reports@osti.gov

Website http://www.osti.gov/contact.html

This report was prepared as an account of work sponsored by an agency of the United States Government. Neither the United States Government nor any agency thereof, nor any of their employees, makes any warranty, express or implied, or assumes any legal liability or responsibility for the accuracy, completeness, or usefulness of any information, apparatus, product, or process disclosed, or represents that its use would not infringe privately owned rights. Reference herein to any specific commercial product, process, or service by trade name, trademark, manufacturer, or otherwise, does not necessarily constitute or imply its endorsement, recommendation, or favoring by the United States Government or any agency thereof. The views and opinions of authors expressed herein do not necessarily state or reflect those of the United States Government or any agency thereof. 
Chemical Sciences Division

Advanced Manufacturing Office

\title{
Additive Manufacturing of Near-net Shaped Permanent Magnets
}

M. Parans Paranthaman ${ }^{1}$, Niyanth Sridharan ${ }^{1}$, Fred A. List $^{1}$, S. S. Babu ${ }^{1}$, Ryan R. Dehoff ${ }^{1}$, Steve Constantinides ${ }^{2}$

${ }^{1}$ Oak Ridge National Laboratory, Oak Ridge, TN 37831, USA

${ }^{2}$ Arnold Magnetic Technologies Corp., Rochester, NY 14625, USA

Date Published: 07/26/2016

\author{
Prepared by \\ OAK RIDGE NATIONAL LABORATORY \\ Oak Ridge, Tennessee 37831-6283 \\ managed by \\ UT-BATTELLE, LLC \\ for the \\ US DEPARTMENT OF ENERGY \\ under contract DE-AC05-00OR22725
}

This report does not contain Protected CRADA information

Approved for Public Release 


\section{CONTENTS}

\section{Page}

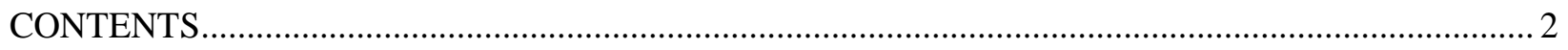

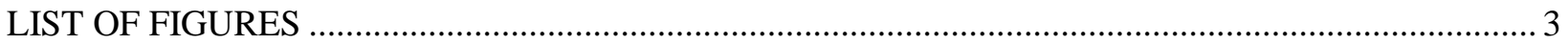

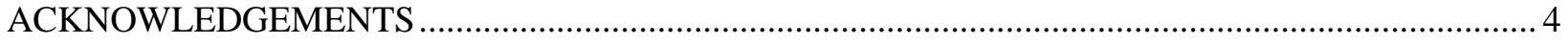

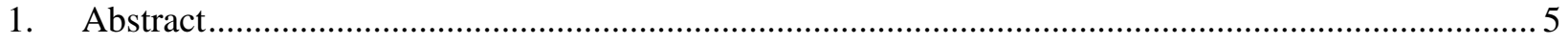

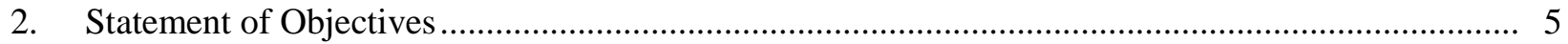

3. Benefits to the Funding DOE Office's Mission …..................................................................... 5

4. Technical Discussion of Work Performed by All Parties ................................................................ 6

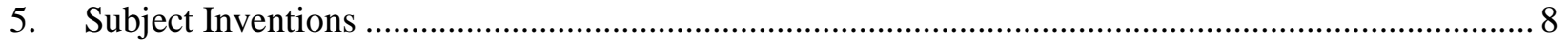

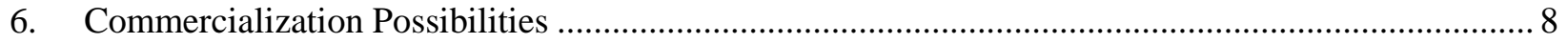

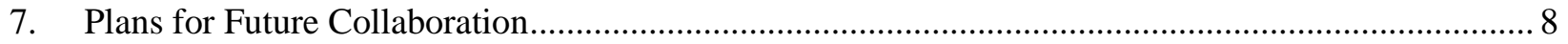

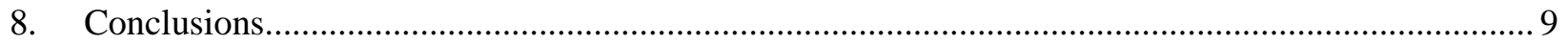

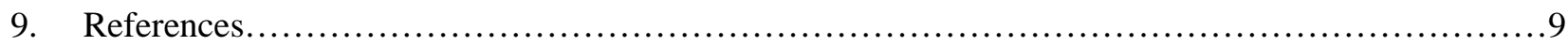




\section{LIST OF FIGURES}

Fig. 1. Cross-sectional optical images of the laser deposited builds ((a) and (b)). SEM images of (c) as received commercial MQP-S-11-9 powders, and (d) Build after laser deposition.

Fig. 2. Magnetization curve of the starting MQP powder and the build. Note the sharp drop in coercivity and remanence of the magnets after processing [10].

Fig. 3. XRD patterns obtained from the powder (shown below in black) and the build (shown above in red). Note the sharp decrease in the intensity of the peaks corresponding to the $\mathrm{Nd}_{2} \mathrm{Fe}_{14} \mathrm{~B}$ hard magnetic phase in the additively manufactured samples. Also note the corresponding increase in the intensity in the alpha iron peak after laser processing. 


\section{ACKNOWLEDGEMENTS}

This CRADA NFE-15-05476 was conducted as a Technical Collaboration project within the Oak Ridge National Laboratory (ORNL) Manufacturing Demonstration Facility (MDF) sponsored by the US Department of Energy Advanced Manufacturing Office (CPS Agreement Number 24761). Opportunities for MDF technical collaborations are listed in the announcement "Manufacturing Demonstration Facility Technology Collaborations for US Manufacturers in Advanced Manufacturing and Materials Technologies” posted at http://web.ornl.gov/sci/manufacturing/docs/FBO-ORNL-MDF-2013-2.pdf. The goal of technical collaborations is to engage industry partners to participate in short-term, collaborative projects within the Manufacturing Demonstration Facility (MDF) to assess applicability and of new energy efficient manufacturing technologies. Research sponsored by the U.S. Department of Energy, Office of Energy Efficiency and Renewable Energy, Advanced Manufacturing Office, under contract DEAC05-00OR22725 with UT-Battelle, LLC. Thanks are due to Niyanth Sridharan from ORNL with the fabrication of builds and Scott McCall from LLNL with magnetic property measurements.

Notice: This manuscript has been authored by UT-Battelle, LLC under Contract No. DE-AC0500OR22725 with the U.S. Department of Energy. The United States Government retains and the publisher, by accepting the article for publication, acknowledges that the United States Government retains a non-exclusive, paid-up, irrevocable, world-wide license to publish or reproduce the published form of this manuscript, or allow others to do so, for United States Government purposes. The Department of Energy will provide public access to these results of federally sponsored research in accordance with the DOE Public Access Plan (http://energy.gov/downloads/doe-public-access-plan). 


\section{Abstract}

The technical objective of this technical collaboration phase I proposal is to fabricate near net-shaped permanent magnets using alloy powders utilizing direct metal deposition technologies at the ORNL MDF. Direct Manufacturing using the POM laser system was used to consolidate $\mathrm{Nd}_{2} \mathrm{Fe}_{14} \mathrm{~B}(\mathrm{NdFeB})$ magnet powders into near net-shape parts efficiently and with virtually no wasted material as part of the feasibility study. We fabricated builds based on spherical NdFeB magnet particles. The results show that despite the ability to fabricate highly reactive materials in the laser deposition process, the magnetic coercivity and remanence of the $\mathrm{NdFeB}$ hard magnets is significantly reduced. X-ray powder diffraction in conjunction with electron microscopy showed that the material experienced a primary $\mathrm{Nd}_{2} \mathrm{Fe}_{17} \mathrm{~B}_{\mathrm{x}}$ solidification due to the undercooling effect $(>60 \mathrm{~K})$. Consequently the presence of alpha iron phase resulted in deterioration of the build properties. Further optimization of the processing parameters is needed to maintain the $\mathrm{Nd}_{2} \mathrm{Fe}_{14} \mathrm{~B}$ phase during fabrication.

\section{Statement of Objectives}

This phase I technical collaboration project (MDF-TC-2016-65) was started on July 31, 2015 and was completed on July 31, 2016. The collaboration partner, Arnold Magnetic Technologies (Arnold) traces its roots back to the late 1800 's. Arnold is one of the only western companies that produces alnico, RECOMA ${ }^{\circledR}$ brand samarium cobalt, ferrite bonded magnets, and neodymium iron boron bonded magnets (both injection molded and compression bonded). In addition they provide assembly capabilities from prototype to production of assemblies from grams to hundreds of kilograms. Arnold is one of the most modern and is the largest U.S. based magnetics company. Today the three main business units are: Precision Magnets and Assemblies Group - magnets, assemblies and reprographics; Precision Thin Metals - ultra-thin metal foil and strip for both magnetic and non-magnetic uses; and Flexmag Industries - flexible bonded magnets (sheet and strip) for the advertising and OEM industries. The main objective of this project is to use additive manufacturing technologies to fabricate near-net shaped permanent magnets with fully dense sintered magnet properties. The magnetic and microstructural properties of the magnets have been characterized and fully evaluated.

\section{Benefits to the Funding DOE Office's Mission}

The use of permanent magnets in green energy technologies has increased dramatically. Rare-earth based permanent magnets are the key components in environmentally friendly technologies such as electric transportation (automotive, marine and aerospace) and direct or hybrid drive wind turbines. The high cost of rare earth raw materials and issues related to adequate and dependable supply of heavy rare earths, e.g. dysprosium, are holding back the adoption or expanded use of these technologies. Considering that a large portion of US rare-earth magnet manufacturing capability was transferred to China in the last decade [1], novel additive manufacturing techniques that avoid or minimize the use of rare-earth elements especially the heavy rare earth elements, need to be developed to reduce US vulnerability to uncertain rare earth material supply and high and volatile pricing [2-7]. Conventional manufacturing methods to make permanent magnets are energy inefficient partly because of the traditional sintering technology but also due to processing material that turns into waste product at or near the end of the manufacturing process. Recycling the waste material is not straight forward. The rare-earth elements tend to oxidize during the manufacturing process (grinding, diamond saw slicing, core drilling, etc.). Therefore, alternative ways need to be explored that not only require less energy during manufacturing but also generate less waste material, especially the fine partially oxidized waste material. One promising technique is a laser-based DMD (Direct Metal Deposition) processing system, where an optical heat energy source such as an industrial dye laser is used to directly fabricate metal parts [2]. The potential 
impacts of research include: developing near net-shape magnets without tooling; and the Critical Materials Institute (CMI) hub additive manufacturing project will benefit from this feasibility study. Overall, the advancement of the utilization of the additive techniques could lead to the adoption of additive manufacturing technology by magnet manufacturing companies and lead to job growth and higher US global manufacturing competitiveness.

\section{Technical Discussion of Work Performed by All Parties}

Additive manufacturing (AM) is a near-net shape manufacturing technique, which can produce final parts with minimal material waste [8]. Several AM techniques are available and are broadly classified based on the nature of the process as powder bed and powder blown [9]. In this work a powder blown directed energy deposition technique, has been used. This process is based on the coaxial laser cladding process where the part is built in layers. The primary process parameters used to control the deposit geometry and part density are the laser power, travel speed and powder feed rate. So far only limited feasibility studies have been attempted to fabricate magnets using additive manufacturing. Since the additive manufacturing process experiences naturally rapid cooling rates, the interface velocities and the solidification structure can be significantly different from those of the conventional manufacturing process. In addition it has been shown that by increasing the solid-liquid interface velocities it is possible to obtain a $\mathrm{Nd}_{2} \mathrm{Fe}_{14} \mathrm{~B}$ microstructure. Due to the rapid interface velocities in the laser DMD processing it is hypothesized to shift the solidification mode from non-magnetic or soft phase such as primary $\gamma$ iron to primary $\mathrm{Nd}_{2} \mathrm{Fe}_{14} \mathrm{~B}$ thereby maximizing the magnetic properties. Hence the aim of this work was to study the feasibility of fabricating NdFeB magnets using the laser powder-blown directed-energy deposition.

Commercial Magnequench anisotropic MQA-38-14 (designated as MQA) and isotropic spherical MQPS-11-9 (designated as MQP) NdFeB powders were used for this study. Fabrication was performed using the DM103D laser directed-energy system with a $1 \mathrm{~kW}$ high power diode laser operating at a wavelength of $910 \mathrm{~nm}$. The depositions were performed under an argon gas blanket, where the oxygen content was $<5$ ppm, to avoid oxidation of the rare earth metals. In addition to the cover blanket a stream of argon was also delivered coaxially along with the powder to shield the melt pool from oxidation and contamination. The builds were fabricated using a laser power of $500 \mathrm{~W}$ a powder feed rate of $5.3 \mathrm{~g} / \mathrm{min}$ and a travel speed of $700 \mathrm{~mm} / \mathrm{min}$. A total of 25 layers were built and the approximate build height was about 12.5 $\mathrm{mm}$ with a height of $0.5 \mathrm{~mm} /$ layer. Following fabrication of the builds, magnetization properties and phase identification of the builds were carried out [10].

As shown in Fig. 1, NdFeB builds were printed. Phase composition, microstructure, and magnetic flux were measured before and after printing to determine the effect of laser deposition on these properties. As shown Fig. 1 (c) and (d), the microstructure changed significantly after laser deposition. Fig. 2 shows the hysteresis loops for both as-received MQP powders and build after laser deposition. The magnetization for the build at $35 \mathrm{kOe}$ reached about $127.2 \mathrm{emu} / \mathrm{g}$ whereas the starting isotropic MQP powder with a theoretical density of $7.43 \mathrm{~g} / \mathrm{cm}^{3}$ reached only $113.0 \mathrm{emu} / \mathrm{g}$. There is a small normal hysteresis $\left(\mathrm{H}_{\mathrm{cB}}\right)$ of 500 Oe retained in this material, but the vast majority of the coercivity was lost after laser processing implying that hard magnetic phase did not survive. Normally the formation of magnetic properties is associated with the formation of the tetragonal $\mathrm{Nd}_{2} \mathrm{Fe}_{14} \mathrm{~B}$ phase. The poor magnetic properties could be attributed to the absence of $\mathrm{Nd}_{2} \mathrm{Fe}_{14} \mathrm{~B}$ or the creation of alternate, possibly soft phases. The poor magnetic properties could be attributed to the absence of $\mathrm{Nd}_{2} \mathrm{Fe}_{14} \mathrm{~B}$. XRD patterns obtained from the as-received MQA powder and the as-built sample are shown in Fig. 3. Fig. 3 shows that the as-received powder contained almost $100 \% \mathrm{Nd}_{2} \mathrm{Fe}_{14} \mathrm{~B}$, while the as-built sample showed the presence of additional phases. Peaks belonging to $\mathrm{Nd}_{2} \mathrm{Fe}_{17} \mathrm{~B}_{\mathrm{x}}$ and $\alpha$-Fe phases were identified in addition to the $\mathrm{Nd}_{2} \mathrm{Fe}_{14} \mathrm{~B}$ phase. The lattice parameters of the constituent phases were obtained from the Rietveld refinements. Accordingly, the lattice parameter of alpha-Fe was found to be $\mathrm{a}=2.8701 \AA$, which is close to the literature value [11- 
17]. On the other hand, the lattice parameters of the $\mathrm{Nd}_{2} \mathrm{Fe}_{14} \mathrm{~B}$ phase were calculated to be $\mathrm{a}=8.7963 \AA$, $\mathrm{c}=12.1923 \AA$ and $\mathrm{a}=8.7974 \AA, \mathrm{c}=12.1509 \AA$ for the as-received powder and the as-built sample, respectively. While the a-lattice parameter did not change much, the shift in the c-lattice parameter suggests that there may have been elemental composition change leading to the formation of a magnetically soft phase. To confirm if the shift in the lattice parameter is driven by compositional change atom probe tomography needs to be performed. The observed lattice parameters from the as-built sample agree with those reported for $\mathrm{Nd}_{2} \mathrm{Fe}_{17} \mathrm{~B}_{\mathrm{x}}[16]$. The formation of secondary phases also leads to the diminishing of the desirable hard magnetic phase. The presence of alpha iron will shunt the field internally reducing $\mathrm{H}_{\mathrm{cJ}}$. Hence to rationalize the drop in properties the solidification sequence in the material needs to be understood during non-equilibrium conditions. Typically $\mathrm{Nd}_{2} \mathrm{Fe}_{14} \mathrm{~B}$ is expected to solidify by a primary $\gamma$ iron formation and then subsequently a peritectic reaction occurs where the $\mathrm{L}+\gamma$ iron transforms to the $\mathrm{Nd}_{2} \mathrm{Fe}_{14} \mathrm{~B}$ phase [18]. However due to the rapid cooling rates encountered during the laser deposition process, the peritectic reaction can be suppressed which results in the absence of the $\mathrm{Nd}_{2} \mathrm{Fe}_{14} \mathrm{~B}$ in the build $[11,13,16]$.
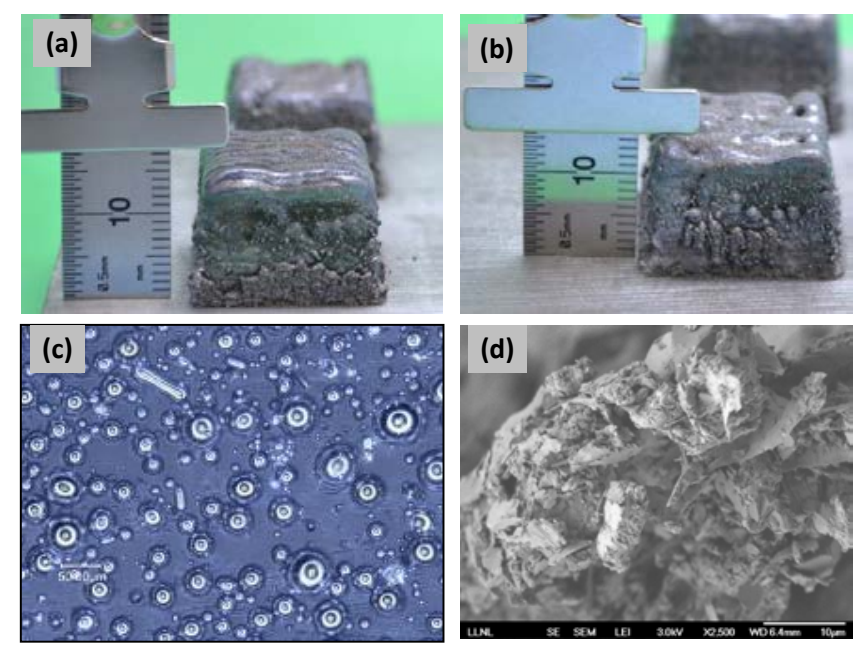

Fig. 1. Cross-sectional optical images of the laser deposited builds ((a) and (b)). SEM images of (c) as received commercial MQP-S-11-9 powders, and (d) Build after laser deposition.

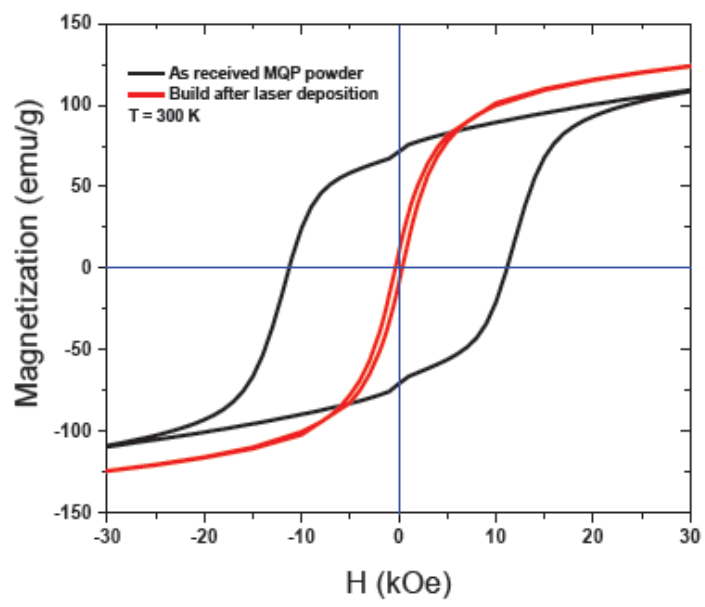

Fig. 2. Magnetization curve of the starting MQP powder and the build. Note the sharp drop in coercivity and remanence of the magnets after processing [10]. 


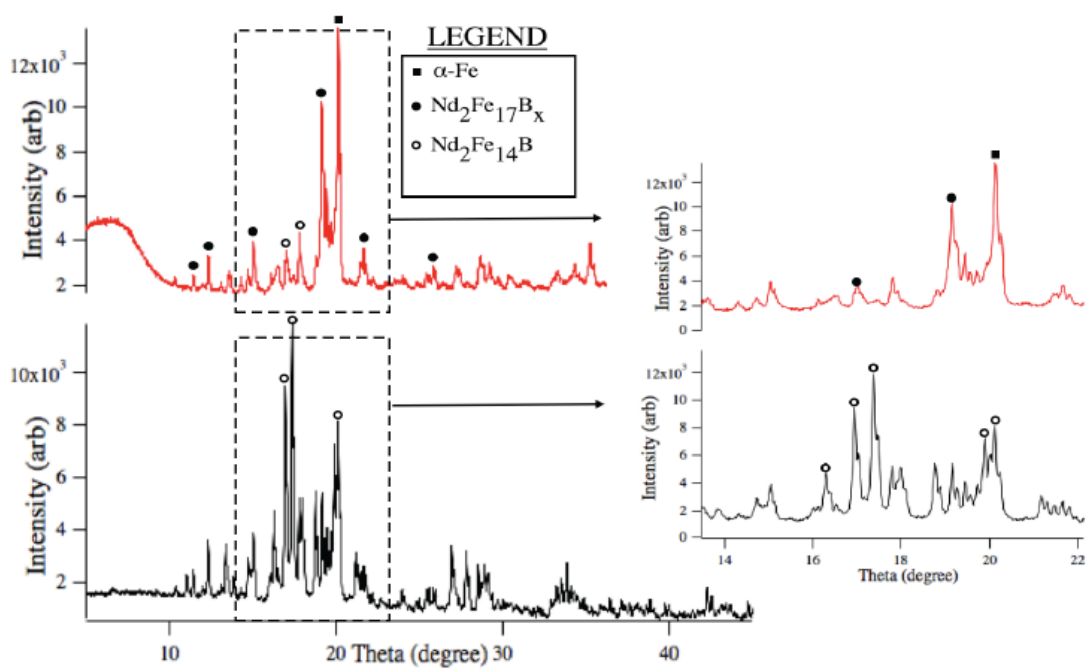

Fig. 3. XRD patterns obtained from the powder (shown below in black) and the build (shown above in red). Note the sharp decrease in the intensity of the peaks corresponding to the $\mathrm{Nd}_{2} \mathrm{Fe}_{14} \mathrm{~B}$ hard magnetic phase in the additively manufactured samples. Also note the corresponding increase in the intensity in the alpha iron peak after laser processing [10].

It is clear that to prevent the loss in the coercivity and remanence in the build it is necessary to retain the $\mathrm{Nd}_{2} \mathrm{Fe}_{14} \mathrm{~B}$ phase. Hence we need to engineer the solidification sequence so that the build solidifies as a primary $\mathrm{Nd}_{2} \mathrm{Fe}_{14} \mathrm{~B}$. This can be promoted by maintaining an undercooling of $<60 \mathrm{~K}$ to facilitate nucleation. The undercooling can be controlled by careful selection of process parameters and by controlling the interface growth velocities. In addition post process thermal solutionizing may also help in decomposing the non-equilibrium $\mathrm{Nd}_{2} \mathrm{Fe}_{17} \mathrm{~B}_{\mathrm{x}}$ and the formation of $\mathrm{Nd}_{2} \mathrm{Fe}_{14} \mathrm{~B}$ phase in the build.

\section{Subject Inventions (As defined in the CRADA)}

Further investigation of direct metal deposition is needed to explore the possibility of new invention. The following manuscript will be published based on some of the results from this research:

N. Sridharan, E. Cakmak, Fred A. List, Huseyin Ucar, Steve Constantinides, S.S. Babu, Scott K. McCall, and M. Parans Paranthaman, "Rationalization of solidification mechanism of neodymiumiron-boron magnet obtained after laser directed-energy deposition process,” (2016) (submitted).

\section{Commercialization Possibilities}

Additively printed sintered magnets offer a better option for making low cost intricate shapes from magnet powder feed. Here we evaluated a novel alternate approach - direct metal deposition (DMD) - to fabricate near-net-shape isotropic $\mathrm{NdFeB}$ magnets. Magnetic and microstructural characterizations indicate that while magnetization $\left(4 \pi \mathrm{M}_{\text {sat }}\right)$ was improved, the permanent magnetic properties degraded as a result of laser deposition. Further process improvements are needed in order to improve coercivity $\left(\mathrm{H}_{\mathrm{CJ}}\right)$ to compete with sintered magnets.

\section{Plans for Future Collaboration}


Additive manufacturing offers significant advantages such as cost effectiveness (no tooling required), fast speed (simple procedure), and capability of producing parts unlimited in size and shape. Therefore, DMD provides an effective method in realizing arbitrary shape with minimum cost and waste, and has the potential to revolutionize large-scale industry production of sintered magnets. In the future work, the effect of laser powder and post annealing will be investigated. Following this work, ORNL plans to continue working with Arnold to develop an additive process towards the goal of achieving printed magnets with much improved magnet properties that are suitable for many industrial magnet applications.

\section{Conclusions}

In this work, we report the feasibility of using the directed energy additive manufacturing technique to handle reactive rare earth elements without any significant loss of alloying elements. Though builds were successfully fabricated the magnetic properties were significantly reduced from that of the starting alloy. X-Ray diffraction showed a large fraction of $\mathrm{Nd}_{2} \mathrm{Fe}_{17} \mathrm{~B}_{\mathrm{x}}$ and some $\mathrm{Nd}_{2} \mathrm{Fe}_{14} \mathrm{~B}$ along with a significant fraction of $\alpha$-Fe. Further process optimization is necessary to improve the magnetic properties.

\section{References}

1. L. H. Lewis, F. Jimenez-Villacorta, Metallurgical and Materials Transactions A, 44A, S2, (2013).

2. ORNL Manufacturing Demonstration Facility website: http://web.ornl.gov/sci/manufacturing/research/additive/

3. M.J. Kramer, R.W. McCallum, A. Anderson, S. Constantinides, Prospects for Non-Rare Earth Permanent Magnets for Traction Motors and Generators, JOM DOI: 10.1007/s11837-012-0351z, June 29, 2012

4. D. Hopkinson, A. Cockburn, W. O'Neill, Fiber laser processing of amorphous rare earth NdFeB magnetic materials, 30th International Congress on Applications of Lasers and Electro-Optics, ICALEO 2011

5. M.A. Willard, Challenges of Magnetic Material Development for Vehicle Electrification, TMS 2013

6. O. Gutfleisch, Controlling the Properties of High Energy Permanent Magnetic Materials by Different Processing Routes, J. Phys. D: Appl. Phys. 33 (2000) R157-R172

7. W. Rodewald, M. Katter, B. Wall, R. Blank, W. Fernengel, Evaluation of Alternative Processing Routes for NdFeB Magnets, Vacuumschmelze

8. I. Gibson, D.W. Rosen, B. Stucker. Additive manufacturing technologies, Springer, 2010.

9. D. Gu, W. Meiners, K. Wissenbach, R. Poprawe. Laser additive manufacturing of metallic components: materials, processes and mechanisms, International materials reviews 57 (2012) 133-164.

10. N. Sridharan, E. Cakmak, Fred A. List, Huseyin Ucar, Steve Constantinides, S.S. Babu, Scott K. McCall, and M. Parans Paranthaman, "Rationalization of solidification mechanism of neodymium-iron-boron magnet obtained after laser directed-energy deposition process,” (2016) (submitted).

11. J. Gao, T. Volkmann, D. Herlach. Undercooling-dependent solidification behavior of levitated $\mathrm{Nd}_{14} \mathrm{Fe}_{79} \mathrm{~B}_{7}$ alloy droplets, Acta materialia 50 (2002) 3003-3012.

12. J. Gao, T. Volkmann, D. Herlach. Metastable solidification of NdFeB alloys by drop-tube processing, Journal of Materials Research 16 (2001) 2562-2567.

13. J. Gao, T. Volkmann, S. Roth, W. Löser, D. Herlach. Phase formation in undercooled NdFeB alloy droplets, Journal of magnetism and magnetic materials 234 (2001) 313-319.

14. J. Gao, T. Volkmann, S. Yang, S. Reutzel, D. Herlach, X. Song. Crystallization of $\mathrm{Nd}_{2} \mathrm{Fe}_{17} \mathrm{~B}_{\mathrm{x}}$ from stoichiometric melt composition, Journal of alloys and compounds 433 (2007) 356-362. 
15. J. Li, Y. Liu, S. Gao, M. Li, Y. Wang, M. Tu. Effect of process on the magnetic properties of bonded NdFeB magnet, Journal of magnetism and magnetic materials 299 (2006) 195-204.

16. T. Volkmann, J. Strohmenger, J. Gao, D.M. Herlach. Observation of a metastable phase during solidification of undercooled $\mathrm{Nd}-\mathrm{Fe}-\mathrm{B}$ alloy melts by in situ diffraction experiments using synchrotron radiation, Applied physics letters 85 (2004) 2232-2234.

17. S. Ozawa, K. Kuribayashi, S. Hirosawa, S. Reutzel, D. Herlach. Heat treatment of metastable $\mathrm{Nd}_{2} \mathrm{Fe}_{17} \mathrm{~B}_{\mathrm{x}}$ phase formed from undercooled melt of Nd-Fe-B alloys, Journal of applied physics 100 (2006) 123906.

18. G. Schneider, F.J. Landgraf, F.P. Missell. Additional ferromagnetic phases in the Fe-Nd-B system and the effect of a $600^{\circ} \mathrm{C}$ annealing, Journal of the Less Common Metals 153 (1989) 169-180. 